\title{
Evaluating students' experience of an integrated assessment: A case study in health promotion
}

\author{
Natisha Dukhi ${ }^{*}$, Sue Southwood ${ }^{2}$ and Sunitha C Srinivas ${ }^{3}$ \\ ${ }^{1}$ Faculty of Pharmacy Rhodes University, Grahamstown, South Africa \\ ${ }^{2}$ Centre for Higher Education Research, Teaching \& Learning (CHERTL), Rhodes University, Grahamstown, South Africa \\ ${ }^{3}$ Associate Professor Rhodes University, Grahamstown, South Africa
}

\begin{abstract}
Objectives: To explore the engagement of second year pharmacy students in a South African University, in the implementation and evaluation of an integrated assignment. Methods: The integrated assignment focused on integrating the concepts of health promotion and pharmacotherapy of chronic non communicable diseases in the Anatomy and Physiology course. On completion, students engaged in a process of evaluation that focused on reflection of the assignment experience and their skills development. Results: Insights from the evaluation process revealed ways in which the assignment was educational and empowering. The students positively highlighted their ability to understand the link between various courses in Pharmacy after doing this integrated assignment, enhanced understanding of addressing chronic non communicable diseases, team building and communication skills. Conclusion: The students' feedback highlighted that the assignment facilitated the achievement of conceptual integration, skills development and positively influenced their understanding of health promotion. The constructive engagement with the students created a space for reflection and facilitated a conducive environment for students to think freely, creatively and recognize the need for health promotion in their role as future pharmacists.
\end{abstract}

Keywords: 'Evaluation', 'Health promotion', 'Integrated assessment', 'Pharmacy', 'chronic non communicable diseases

\section{INTRODUCTION}

The focus of this paper is a case study of an integrated assignment in second year undergraduate Pharmacy course in a South African university. The notion of integration is a conceptual one, referring to the integration of health promotion within the curricular context of Anatomy \& Physiology. As an innovative curricular activity it was considered worth giving specific attention to and evaluating how it was experienced by the students. An externally facilitated process of evaluation led to the identification of five strong themes around the learning experience considered to hold much significance in the consideration of such curricular engagement.

\section{MATERIALS AND METHODS}

\section{Intervention}

The context of the study presented here is a second year cohort of students in the Faculty of Pharmacy at Rhodes University, in the Eastern Cape of South Africa. Two lecturers, one coordinating second year Anatomy and Physiology (A\&P) and one coordinating third year Pharmacy Administration and Practice (PAP), collaborated in the planning, implementation and evaluation of a specific teaching and learning project, involving student active engagement in an integrated assignment. This involved the incorporation of new global knowledge on Chronic Non Communicable Diseases (CNCDs) and health promotion within the curricular space of A\&P. The rationale
DOI: 10.5530/ijper.48.3.1

Address for correspondence: Ms. Natisha Dukhi BMed Sci, BSc (Hons), $M$ Med Science, Int Dip Clin Nutr, Faculty of Pharmacy, Rhodes University, Grahamstown, South Africa

Phone: +27 (0) 466037428

Fax: +27 (0) 466361205

E-mail: n.dukhi@ru.ac.za

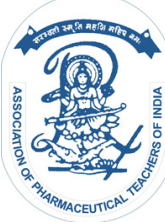

www.ijper.org 
for this conceptual integration is aimed at generating awareness and understanding around the urgent health challenges facing 'developing' countries. CNCDs are increasing at an epidemic level, especially in low and middle income countries, South Africa being one of 23 'developing' countries that contributes towards $80 \%$ of the global chronic disease mortality burden. ${ }^{1}$

\section{Assignment}

The integrated assignment discussed in this case study was planned and implemented for second year pharmacy students based on prior experiences of health promotion and service - learning courses developed and implemented for final year pharmacy students. ${ }^{2,3}$ Before initiating the assignment, CNCDs affecting South Africa were introduced to the students and requirements of the integrated assignment and the assessment criteria were explained. The assignment was designed to encourage students to see the 'big picture' of integrating human body systems knowledge from A\&P in second year, with third year subjects such as Pharmacy Administration and Practice (PAP) and Pharmacotherapy. Integration with pharmacotherapy came in the form of learning concepts in medical conditions and treatment using the South African Standard Treatment Guidelines (STGs), while integration with PAP required using three sources (primary, secondary and tertiary) of information, health promotion and communication skills, specifically the collaborative development of PowerPoint presentations and presentation to the class.

Students were assigned to groups and each group was provided with a published peer reviewed article on hypertension, diabetes mellitus or obesity, as a primary source of information. Students were required to use Micromedex ${ }^{\circledR}$ (a medicines information database that is widely used by pharmacy students during third and fourth year of study) as a secondary source of information. Students were also required to consult the STGs and standard pharmacology textbooks as a tertiary source of information. Students completed the first draft of their PowerPoint presentation based on an assessment grid, outlining the intended outcomes and the related criteria to be met. The lecturer provided prompt formative feedback on the first draft to ensure all groups had sufficient time to make changes prior to their presentations. Once feedback was provided, students had to incorporate changes into their presentation and had the option of resubmitting the second draft to the lecturer for feedback. While the first draft of the assignment was assessed purely formatively, the final presentation was assessed summatively, based on self, peer and lecturer assessment. Each group had to submit the self-assessment as part of the final assign- ment report, while peer and lecturer assessments were recorded when the students completed their presentations.

\section{Data collection}

Student reflection on and evaluation of the practice and experience of the assignment took the form of a small group instructional diagnosis (SGID), ${ }^{4}$ facilitated by a member of the University's Center for Higher Education Research Teaching and Learning (CHERTL). The aim of this discussion was to gather information on the students' experience of the integrated assignment, both formatively and summatively. The class consisting of 96 students was divided into four smaller focus groups to allow space for more in-depth discussion. In each case, the facilitator started by explaining the purpose of engaging in the SGID and outlining the processes involved.

\section{Data Analysis}

The SGID was framed by a set of questions on handouts provided: 'W hat did you find useful about the integrated assignment? How do you feel the assignment might support integration with other aspects of the degree? How would you improve the assignment? Explain your answer. Any other constructive comments regarding the assignment?' These questions were carefully deliberated, and deliberately appreciative, to both highlight strengths and to generate insights into how the integrated assignment could be developed further in order to improve the opportunities for effective learning. The students were initially given space to think about and record their responses individually. They were then arranged randomly in groups of 4 or 5. Each group of students selected amongst themselves a facilitator and a reporter. The facilitator encouraged everyone to share their reflections, while the reporter took notes and fed back to the larger group. During the group feedback the key ideas were captured by the CHERTL staff member. Analysis of the data (individual, group and class notes) by the CHERTL staff member, led to the identification of five strong interlinking themes: Conceptual integration/ coherence, Content, Skills development, Working with others and Assessment, which are explained below.

\section{RESULTS}

\section{Conceptual integration/coherence}

Students appreciated the links that A\&P afforded with other subjects and to their potential future as practising pharmacists. It was recognised that A\&P linked with health care and development, helped develop understanding in other subjects such as pharmacotherapy, as well as providing them with a good foundation for Phar- 
macy Administration and Practice and pharmaceutical care. Insight into social behaviour, particularly that of potential patients, and the role of pharmacists in health care and development were identified as specific areas of integration. The relationship of theory and practice was also highlighted as an integral strength.

\section{Content}

The students felt that the assignment gave them a good background in, and understanding of, CNCDs, topics of local significance set within the bigger picture - generating both insights into practice locally and implications globally. Relevance and application to real life was also appreciated. Students described the assignment as "informative", particular mention was made of the Standard Treatment Guidelines which they had been previously unaware of.

For the future development of such activity, the need for greater diversity in terms of topics was highlighted. Students felt strongly that there should be a much wider choice of diseases to choose from, each group focusing on a different one. They felt this would make it more interesting and motivating. It was also recommended that focus be placed on diseases which are related to the different systems they learned about in class to help consolidate their understanding. This would mean greater opportunity for learning a wider range of content and would allow for greater personal relevance and appropriacy. In terms of resources, students suggested that a wider variety of articles be provided in future for different aspects and that more is offered in terms of quantity and relevance. (They were reminded at this point of the responsibility they need to be taking for such things themselves!)

\section{Skills Development}

Students recognised that presenting to an audience is something they will have to be able to do in the 'real world' and were pleased to have the opportunity to develop these skills. While the lecturer had provided formative feedback during the development of the presentations, students expressed the desire to have more formative feedback from the lecturer in terms of their presentation skills with constructive comments for improvement in terms of the final presentation. It was felt that some of the presenters were repeating the same mistakes and the group would have benefitted from more structured facilitation and constructive engagement around presentation skills. In order to support this, it was suggested that presentation guidelines were developed and used and that timeframes are adhered to, in order to encourage greater 'professionalism'. It was also suggested that the presentations be spaced out and that more time was allowed for feedback and discussion. In addition to presentation skills, students recognised this experience had also contributed towards raising their confidence and developing their communication, leadership and research skills. In terms of the latter, it was suggested that the assignment was more research based - "so that students could apply what they learn to the community", "to see what is really happening."

\section{Working with others}

Students recognised the importance of engaging in what they recognised as being "more than group work" - "team work" - and the challenge of learning to work with others. There was much discussion about working in groups and the associated advantages and disadvantages. There were issues around logistics for many students. While some felt strongly that one should be able to choose one's team mates - some were frustrated by what they perceived as other students' slackness - it was agreed that this would make it less 'real' and that working in given groups prepares them better for life beyond university. It was suggested that to encourage greater engagement, the group work and lecture work load be considered. It was also suggested that the adoption of different roles and responsibilities within groups was facilitated to encourage student engagement. If doing more than one presentation in A\&P, it was suggested that groups were changed to allow more interaction. The students felt it was a good learning experience in terms of developing tolerance, problem solving skills and communication skills (within and between groups as well as one to one) and contributed towards the development of improved peer relationships. It was also acknowledged that this will prepare them well for future interactions with other health care professionals and patients.

The SGID provided an important space for the students to hear different views in the class and explore different perspectives. This sometimes led to interesting discussions. For example, the question of whether the students should be able to choose their own groups elicited much debate. While some felt strongly that they should be able to do so and others agreed that it would be advantageous in some ways, it was recognized that in terms of preparing them for the future they would need to learn to work with different and sometimes difficult people. This was particularly interesting in highlighting what the students perceived to be the role of the University and the purposes of learning within it.

\section{Assessment}

While some students were not clear about the purpose of the assignment, others regarded the instructions as 
being "specific, good and clear" and the explanation of assessment criteria was particularly appreciated. The students also appreciated the formative feedback the lecturer provided during the development of the assignment. Specific suggestions offered to support future development of the assignment included: students should be assessed on an individual level - this could involve peer assessment on individual participation in, and contribution to, the group project; only the lecturer should assess or peer assessment should be weighted lower; and it was suggested that a workshop was offered to support students in conducting peer assessment.

In general, the assignment was considered as "relevant to us as Africans". It "challenged" the students, taking them "out of their comfort zone" and confronting them with real life situations. It raised their awareness, built their confidence and helped to forge personal relationships.

\section{DISCUSSION}

To address the increased burden of CNCDs globally, it is recognized that an effective strategy is introduction of health promotion early on in the health care professionals' course as an integral part of pharmaceutical care. ${ }^{5}$ Rather than focusing on treatment and management, in pharmacy practice, there has been a paradigm shift allowing pharmacists to become more proactive with their encounters of health issues in the community and health promotion. The focus of this case study has been on the active engagement of pharmacy students in an integrated assignment aimed at offering a learning experience of direct relevance to current pressing health concerns and to the practice of current and future pharmacists. The integration of health promotion in the A\&P course along with other aspects (PAP, pharmacotherapy, etc) early in the Pharmacy programme facilitates clear, specific links for students to embark on a 'connected' journey where educators can highlight to them that 'dots do join' between each course and 'how they join' rather than leaving it to them to see these subtle connections, later on in the Pharmacy programme.

The focus of this case study has been on the pre-service development of pharmacists. Pharmacy students, it is argued, require active learning engagement that will allow them to move beyond concern with 'organisation, presentation and testing of content ${ }^{6}$ towards revising, improving ways of thinking and connecting information learnt in lectures to practice outside the lecture room. ${ }^{7}$ The content developed in this case study was recognised as of relevance both locally and globally and that the assignment involved the development of skills and processes appropriate for life beyond the world of
Pharmacy education. This was particularly emphasised around the notion of working with others, preparing students not only conceptually but also practically for future professional interaction. There is a need for undergraduate educators in developing countries to develop an integrated curriculum ${ }^{3}$ that is relevant to the practice of current and future pharmacists in challenging, under resourced health care settings, especially in the public sector health care system.

Engagement with the evaluation process provided the students with 'a space of opportunity for constructive engagement', a space for 'reflection on student experience and insights to inform future practice, ${ }^{8}$. While pertinent suggestions were made for the future development of this integrated assignment, such as greater emphasis on application and research, the assignment was recognised as offering an engaging and constructive space for learning about the 'real world' of Pharmacy theory and practice and beyond. The integrated assignment facilitated a learning environment that allowed creativity, the ability for students to identify and decipher possible solutions to a problem and see the need for health promotion in their role as future pharmacists.

\section{Limitations of the study}

This case study focuses on the reflections of students on their experience of engaging with an integrated assignment. In order to generate a richer and more 'balanced' picture of the context being evaluated, other lenses could be used to view the situation through. In addition to student evaluation, the lecturers could also have engaged in reflecting on the situation as part of both self and peer evaluation. ${ }^{9}$ These lenses altogether would have contributed to the development of a richer, more textured and more complete 'picture' of the focus of evaluation, looking at the situation from many different angles or perspectives, a more balanced and more valid picture. Nevertheless, feedback from the students alone is still considered to be of value in informing the development of the integrative nature of the course and therefore the learning that the students engage in.

\section{CONCLUSION}

The case study discussed in this paper offers evidence to support the introduction and integration of health promotion and pharmacotherapy early on in undergraduate pharmacy courses. It illustrates how the integration of different courses can enhance the development of future pharmacists, with key skills and competencies that will positively influence their contribution to health promotion and ultimately the prevention of CNCDs affecting developing countries. 


\section{CONFLICTS OF INTEREST}

None Declared

\section{ACKNOWLEDGEMENT}

None Declared

\section{REFERENCES}

1. Abegunde DO, Mathers $C D$, Ortegon M, Strong K. The burden and costs of chronic diseases in low-income and middle-income countries. Lancet. 2007; 370: 1929-38.

2. Srinivas SC, Wrench W, Karekezi C, Radloff S, Daya S. Obesity: A baseline health promotion intervention of an introductory service-learning course for pharmacy students. Health SA Gesondheid. 2009; 14: 1-6.
3. Karekezi CW, Wrench W, Quinn L, Belluigi D, Srinivas SC. Design, Implementation and Preliminary Evaluation of a New Service-Learning Elective for Pharmacy Students. Education as change. 2007; 11: 143-56.

4. Coffman SJ. Improving your teaching through Small-Group Diagnosis. College Teaching. 1991; 39: 80-2.

5. World Health Organization (WHO). The Bangkok Charter for health promotion in the globalized world. [online] 2007 [cited 2013 October 8]. Available from: URL: http://www.who.int/healthpromotion/conferences/6gchp/bangkok_ charter/en/print.html

6. Gibbs G, Coffey M. The impact of training of university educators on their teaching skills, their approach to teaching and the approach to learning of their learners. Active learning in Higher Education. 2004; 5: 87-100.

7. van Amburgh JA, Devlin JW, Kirwin JL, Qualters DM. A tool for measuring active learning in the classroom. Am J Pharm Educ. 2007; 71: 85.

8. Southwood SL. Small Group Instructional Diagnosis Working document. Unpublished evaluation resource; 2009

9. Brookfield SD. Becoming a critically reflective teacher. San Francisco: Jossey-Bass; 1995. 